\title{
Effect of Nitrogen on Low Cycle Fatigue Behavior of Austenitic Stainless Steel*
}

\section{By Toshihiko TAKEMOTO,** Koji MUKAI** and Kazuo HOSHINO***}

\begin{abstract}
Synopsis
The effect of nitrogen on low cycle fatigue behavior of $18.5 \mathrm{Cr}-15 \mathrm{Ni}$ austenitic stainless steel has been investigated over a temperature range from room temperature to $-162^{\circ} \mathrm{C}$. Results obtained are as follows :

(1) $\mathrm{N}$ induces cyclic hardening, followed by cyclic softening to saturation over the whole temperature range.

(2) The cyclic softening at room temperature may be attributed to dislocation rearrangement from planar arrays to cellular ones, while at $-162{ }^{\circ} \mathrm{C}$, it may be attributed to the increase in mobile dislocation density.

(3) Based on these results, it is proposed that a zone of short range order $(S R O)$ may be formed by the addition of $\mathrm{N}$, and the interaction between dislocations and the SRO-zone may be responsible for the observed cyclic behaviors. Especially at $-162{ }^{\circ} \mathrm{C}$ the cyclic behavior is controlled by a thermally activated process of dislocation motion in a short range stress field.

(4) $\mathrm{N}$ improves the fatigue life over the whole temperature range by reducing cyclic hardening and promoting cyclic softening.
\end{abstract}

\section{Introduction}

$\mathrm{Cr}-\mathrm{Ni}$ austenitic stainless steels, owing to their excellent low temperature toughness as well as good workability and weldability, are widely used as structural materials for low temperature usages such as LNG industry. Moreover, in recent years, new materials having high strength and high ductility at cryogenic temperatures are highly required in the fields of energy industry, such as MHD electric power generator and unclear fusion reactor. Thus, the knowledge of mechanical properties of austenitic stainless steels at low temperatures is highly desirable.

Low cycle fatigue behaviors of metastable austenitic stainless steels have been investigated. ${ }^{1)}$ It was clarified that a deformation induced martensite $\left(\alpha^{\prime}\right)$, which increases the cyclic hardening rate, deteriorates the fatigue properties. On the other hand, it is well known that $\mathrm{N}$ is an important interstitial alloying element to improve mechanical properties at cryogenic temperatures and that microscopically the addition of $\mathrm{N}$ induces a planar distribution of dislocations. However, the effect of $\mathrm{N}$ on fatigue properties has not been intensively investigated so far.
The purpose of the present paper is to assess the effect of $\mathrm{N}$ on low cycle fatigue behavior of austenitic stainless steel which is stable with respect to martensitic transformation.

\section{Experimental Procedures}

Chemical compositions of alloys used in the present investigation are shown in Table 1. The base alloy is $18.5 \mathrm{Cr}-15 \mathrm{Ni}$. L Steel contains low $\mathrm{N}$ and $\mathrm{N}$ steel has high $\mathrm{N}$ content. These steels were melted in $30 \mathrm{~kg}$ and $50 \mathrm{~kg}$ high frequency vacuum induction furnaces. They were forged to $30 \mathrm{~mm} \phi$ and heat treated for $1 \mathrm{hr}$ at $1100{ }^{\circ} \mathrm{C}$. They were then cold swaged to $18.5 \mathrm{~mm} \phi$, finally annealed at $1050{ }^{\circ} \mathrm{C}$ and water quenched. The annealing time was controlled so that the grain sizes were about $30 \mu \mathrm{m}$ in diameter.

Specimens had a gauge length of $25 \mathrm{~mm}$ and a diameter of $8 \mathrm{~mm}$. Fatigue test was performed under controlling total strain range $\left(\varepsilon_{t}\right)$ in tension-compression triangle wave. The strain rate was $10^{-3} \mathrm{sec}^{-1}$ and the testing temperatures used were room temperature $(R T),-100{ }^{\circ} \mathrm{C}$ and $-162{ }^{\circ} \mathrm{C}$. Hysteresis loops were automatically recorded at a preset interval and changes in stress range $(\sigma)$ and plastic strain range $\left(\varepsilon_{p}\right)$ were measured with respect to the number of cycles. Figure 1 shows an example of hysteresis loop. The amount of martensite $\left(\alpha^{\prime}\right)$ induced by fatigue deformation was measured by sample vibrating magnetometer. ${ }^{4)}$ Specimens for microstructural observation were fatigued at predetermined numbers of cycles. The specimens were then sliced into $0.25 \mathrm{~mm}^{t} \times$ $3 \mathrm{~mm} \phi$ by spark errosion machine and thin foils were prepared by twin-jet electropolishing technique. The electropolishing solution was a mixture of $10 \% \mathrm{HClO}_{4}$ and $90 \% \mathrm{CH}_{3} \mathrm{COOH}$. The thin foils were observed in a transmission electron microscope operated at $200 \mathrm{kV}$. In this case, in order to eliminate the influence of loading direction on the microstructure, special care was taken so that grains which have loading direction of shaded area in Fig. 2 were selected.

Table 1. Chemical composition of alloys. (wt \%)

\begin{tabular}{|c|c|c|c|c|c|c|c|c|}
\hline Sample & C & $\mathrm{Si}$ & $\mathrm{Mn}$ & $P$ & $\mathrm{~S}$ & $\mathrm{Cr}$ & $\mathrm{Ni}$ & $\mathrm{N}$ \\
\hline L steel & 0.015 & 0.52 & 1.03 & 0.018 & 0.014 & 18.72 & 14.96 & 0.005 \\
\hline $\mathrm{N}$ steel & 0.011 & 0.57 & 0.92 & $\operatorname{tr}$ & 0.011 & 18.32 & 14.87 & 0.144 \\
\hline
\end{tabular}

* Originally published in Nisshin Steel Technical Report, (1984), No. 51, 8, in Japanese. English version received on August 23, 1985; accepted in the final form on December 6, 1985. (C) 1986 ISIJ

** Shunan R \& D Laboratories, Nisshin Steel Co., Ltd., Tonda, Shinnanyo 746.

*** Shunan Works, Nisshin Steel Co., Ltd., Tonda, Shinnanyo 746. 


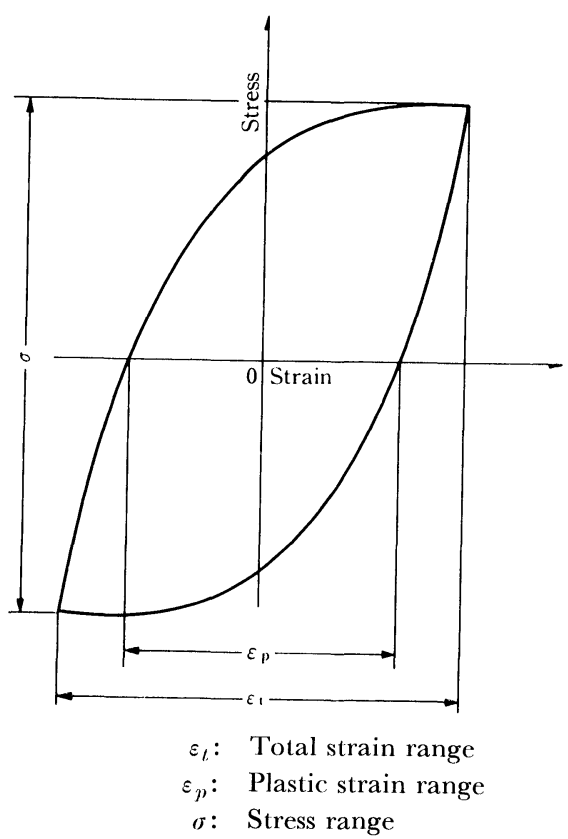

Fig. 1. Schematic hysteresis loop.

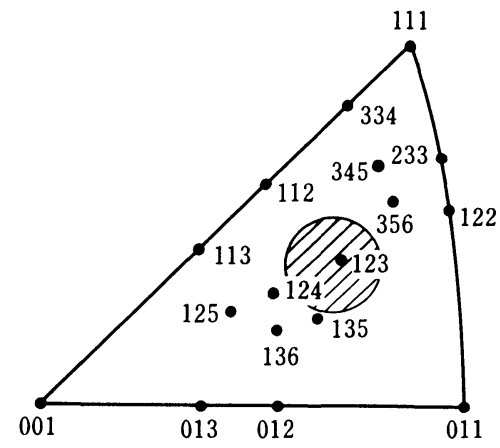

Fig. 2. Loading direction of grain selected for dislocation structure analysis.

\section{Results}

\section{Fatigue Life and Amount of Martensite Induced by Fatigue}

Figure 3 shows the relation between $\varepsilon_{t}$ and $n_{f}$ at various temperatures, where $n_{f}$ is the number of cycles to failure. It can be seen that at room temperature $n_{f}$ of $\mathrm{N}$ steel is a little longer than that of $\mathrm{L}$ steel at any applied strain range. It is also noted that while $n_{f}$ of $\mathrm{L}$ steel decreases with lowering testing temperature, $n_{f}$ of $\mathrm{N}$ steel increases as the testing temperature decreases.

The amount of $\alpha^{\prime}$ induced in $\mathrm{L}$ steel after fatigue failure is shown in Fig. 4. When the steel is cycled at room temperature, $\alpha^{\prime}$ is not detected at any applied strain range. However, when the steel is fatigued at $-100^{\circ} \mathrm{C}$ at a high applied strain range several percents of $\alpha^{\prime}$ are induced. Moreover, when the testing temperature is $-162{ }^{\circ} \mathrm{C}, \alpha^{\prime}$ induced is about $20 \%$ at $\varepsilon_{t}$ of $1.5 \%$. On the other hand, $\alpha^{\prime}$ in $\mathrm{N}$ steel is not detected at any applied strain level over the whole temperature range. These results suggest that the fatigue behavior of the present alloy is not influenced by $\alpha^{\prime}$, except for $\mathrm{L}$ steel fatigued at $-162{ }^{\circ} \mathrm{C}$.

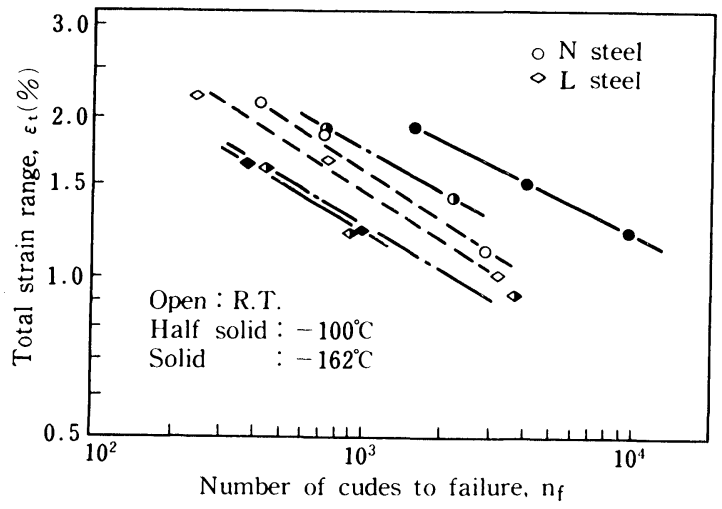

Fig. 3. Relation between $\log \varepsilon_{t}$ and $n_{f}$ at various temperatures.

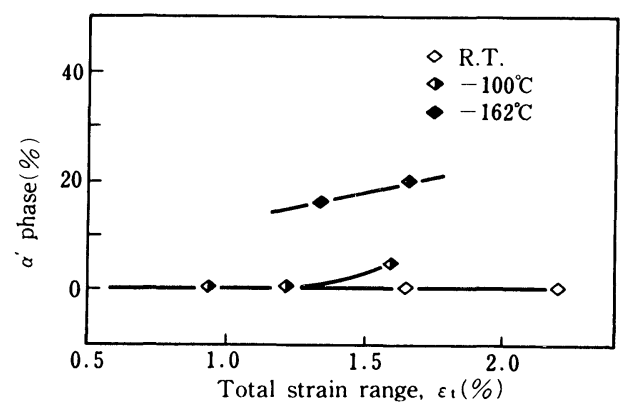

Fig. 4. Amount of $\alpha^{\prime}$ phase induced by cyclic deformation at various temperatures for $\mathrm{L}$ steel.

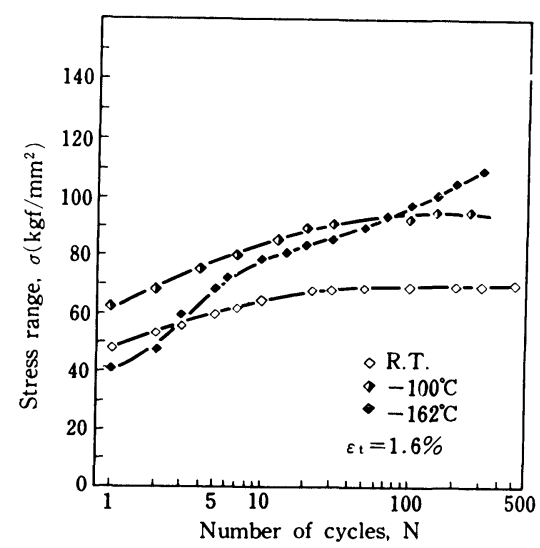

Fig. 5. Cyclic behavior of $\mathrm{L}$ steel at various temperatures.

\section{Cyclic Deformation Behavior}

Figure 5 shows cyclic deformation behaviors of $\mathrm{L}$ steel at $\varepsilon_{t}=1.6 \%$ at various temperatures. At room temperature the steel exhibits a cyclic hardening at an early stage of deformation, followed by cyclic saturation. At the testing temperature of $-100^{\circ} \mathrm{C}$, a similar behavior of cyclic hardening to saturation is observed, although the stress range is higher than that at room temperature. In contrast, when the steel is fatigued at $-162{ }^{\circ} \mathrm{C}$, no cyclic hardening to saturation is observed and cyclic hardening takes place continuously during cyclic deformation.

Figure 6 shows the cyclic deformation behavior of $\mathrm{N}$ steel at $\varepsilon_{t}=1.6 \%$. It should be noted that the cyclic deformation behavior of $\mathrm{N}$ steel is completely 


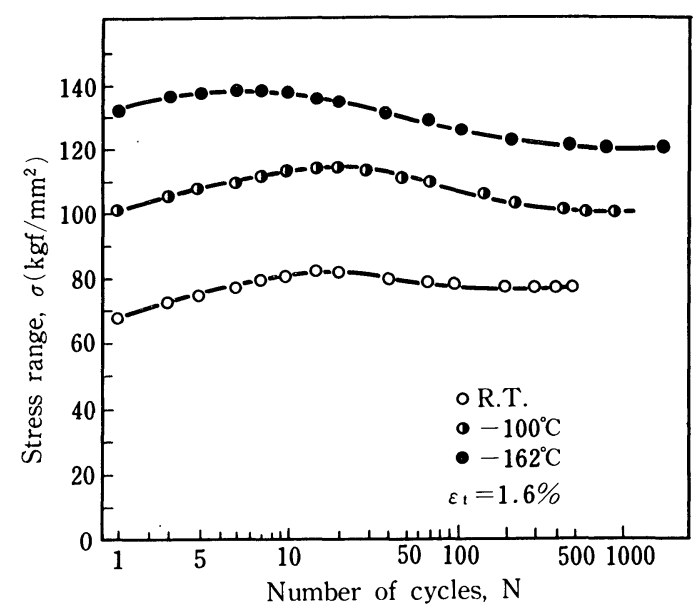

Fig. 6. Cyclic behavior of $\mathrm{N}$ steel at various temperatures.

different from that of $\mathrm{L}$ steel at any testing temperature. $\mathrm{N}$ steel exhibits a cyclic hardening at an early stage of cycling, followed by cyclic softening to saturation. The numbers of cycles at which the stress range reaches a peak stress are about 15 cycles and 7 cycles at room temperature and $-162{ }^{\circ} \mathrm{C}$, respectively. The change in stress range in the cyclic softening stage is shown in Fig. 7, where $\Delta \sigma_{s}$ represents the amount of softening from peak stress $\left(\sigma_{p}\right)$. It can be seen that as the testing temperature decreases, $\Delta \sigma_{s}$ increases and the number of cycles to saturation also increases.

Figure 8 shows the effect of testing temperature on stress range at the first cycle $\left(\sigma_{n=1}\right)$, peak stage $\left(\sigma_{p}\right)$ and saturation stage $\left(\sigma_{s}\right)$, respectively. Since L steel exhibits no cyclic softening, $\sigma_{s}=\sigma_{p} . \quad \sigma_{n=1}$ of $\mathrm{N}$ steel increases substantially with decreasing testing temperature, compared with that of $\mathrm{L}$ steel. This indicates that the stress range of $\mathrm{N}$ steel at an early stage of cyclic deformation exhibits a strong temperature dependence. In contrast, temperature dependences of $\sigma_{p}$ and $\sigma_{s}$ of $\mathrm{N}$ steel are similar to those of $\mathrm{L}$ steel.

Figure 9 shows the difference of stress range at the peak stage and the saturation stage from the first cycle, where $\Delta \sigma_{h}=\sigma_{p}-\sigma_{n=1}, \Delta \sigma_{s}^{*}=\sigma_{s}-\sigma_{n=1}$. It can be seen that at room temperature, $\Delta \sigma_{h}$ of $\mathrm{N}$ steel is smaller than that of $\mathrm{L}$ steel. As the temperature decreases, $\Delta \sigma_{h}$ of $\mathrm{L}$ steel increases but that of $\mathrm{N}$ steel decreases. It should be noted that $\Delta \sigma_{s}^{*}$ of $\mathrm{N}$ steel also decreases with lowering temperature and becomes negative below $-100^{\circ} \mathrm{C}$.

\section{Change in Microstructure during Cyclic Deformation}

Photograph 1 represents the change in microstructure of $\mathrm{L}$ steel fatigued at room temperature. (a) shows a dislocation structure after 5 cycles (during cyclic hardening stage). Dislocations tangle each other and a cellular type of dislocation structure is formed. (b) shows a well developed cell structure after cyclic hardening to saturation is attained.

Photograph 2 represents the change in microstructure of $\mathrm{L}$ steel fatigued at $-162{ }^{\circ} \mathrm{C}$. (a) shows a dislocation structure at an early stage of cyclic deformation. It can be seen that dislocations exhibit a more planar type of arrays than those observed in Photo.

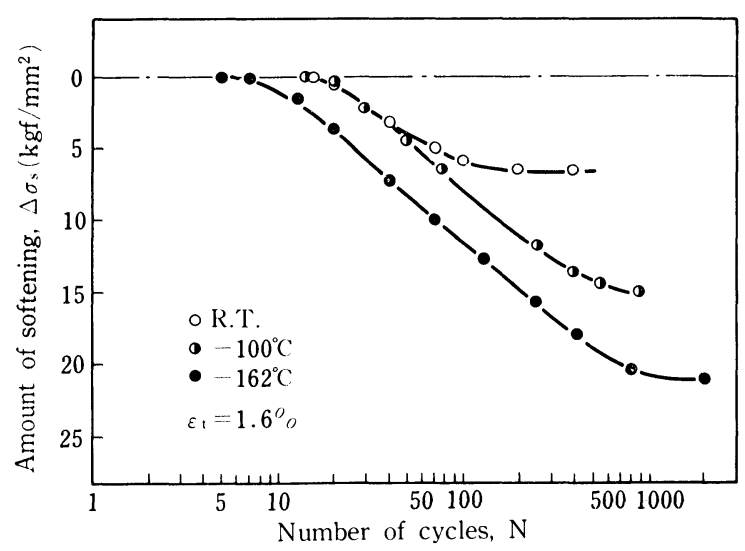

Fig. 7. Effect of temperature on cyclic softening behavior of $\mathrm{N}$ steel.

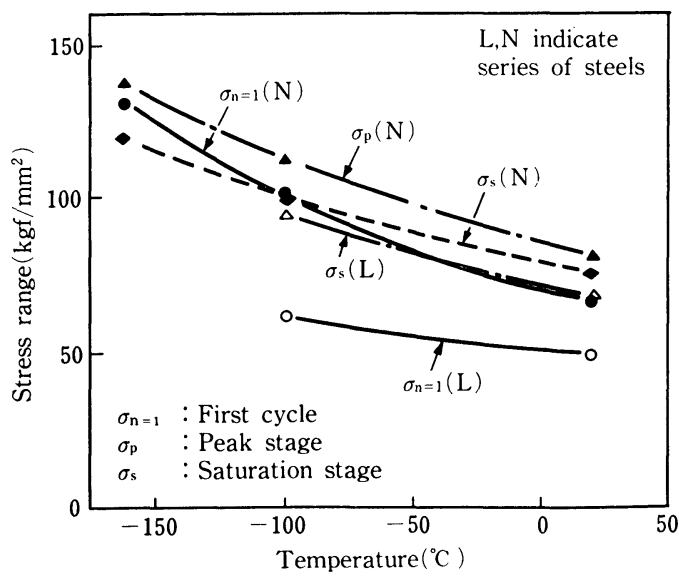

Fig. 8. Temperature dependence of stress range at first cycle, peak and saturation stages $\left(\varepsilon_{t}=1.6 \%\right)$.

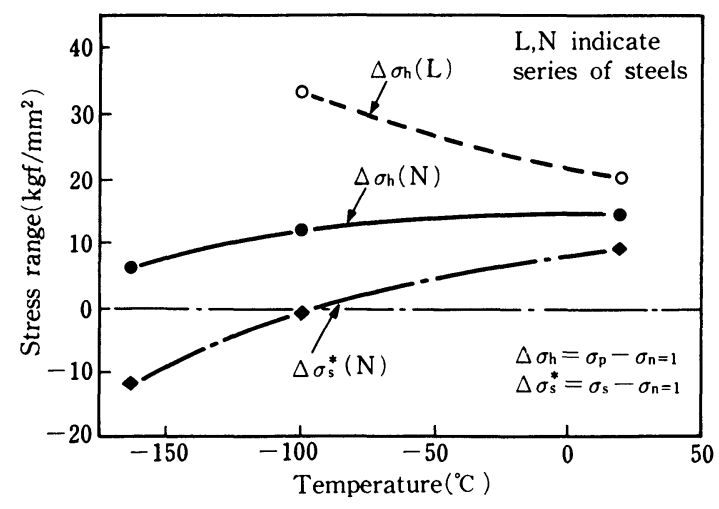

Fig. 9. Effect of temperature on change in stress range during cyclic hardening-softening $\left(\varepsilon_{t}=1.6 \%\right)$.

1(a). (b) represents a microstructure during cyclic hardening stage. $\quad \alpha^{\prime}$ phase is formed frequently at intersections of slip bands in the matrix. Therefore, it is concluded that $\alpha^{\prime}$ phase induced by cyclic deformation is responsible for the continuous cyclic hardening.

Photograph 3 represents dislocation structures of $\mathrm{N}$ steel fatigued at room temperature. (a) shows a dislocation structure after 5 cycles (during hardening stage). Dislocations are distributed uniformly in the matrix and a planar type of dislocation structure is 


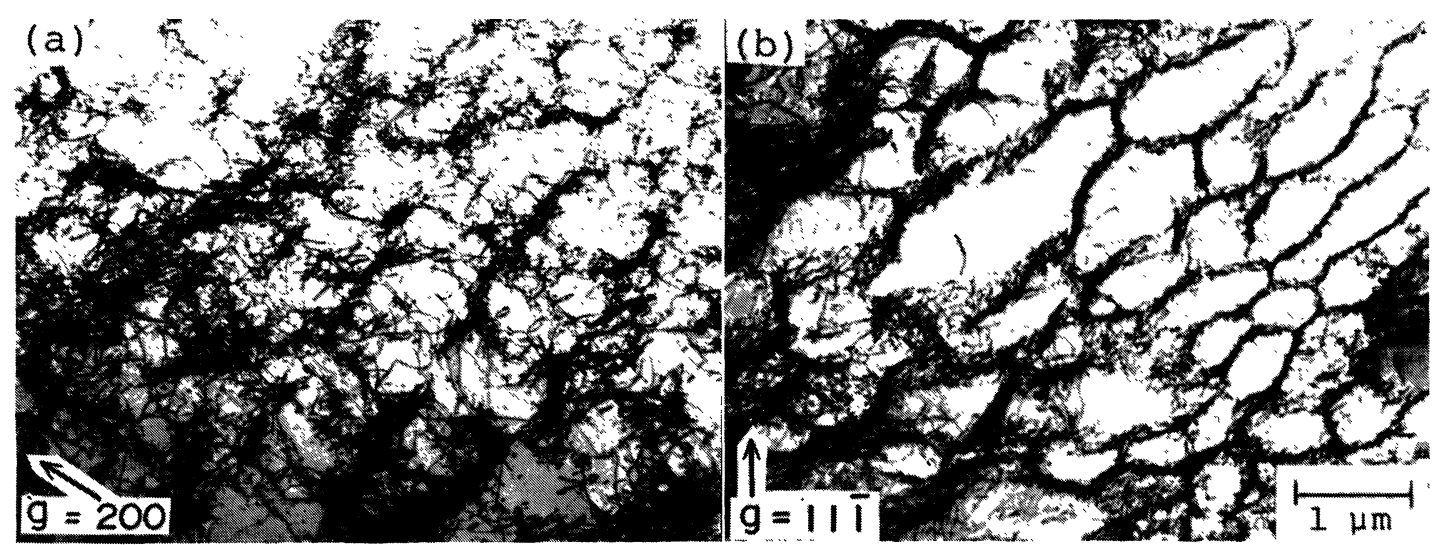

$\begin{array}{ll}\text { (a) } 5 \text { cycles } & \text { (b) } 250 \text { cycles }\end{array}$

Photo. 1. Dislocation structure of L steel fatigued at $\varepsilon_{l}=1.6 \%$, room temperature.

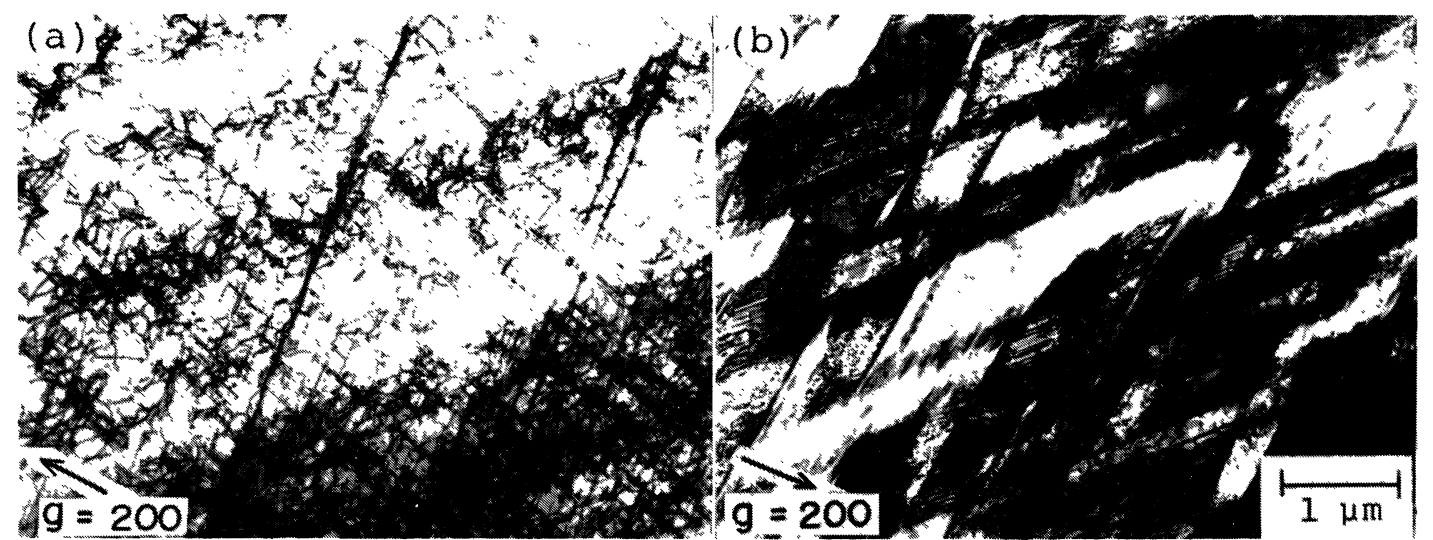

$\begin{array}{ll}\text { (a) } 5 \text { cycles } & \text { (b) } 250 \text { cycles }\end{array}$

Photo. 2. Dislocation structure of $\mathrm{L}$ steel fatigued at $\varepsilon_{t}=1.6 \%,-162{ }^{\circ} \mathrm{C}$.

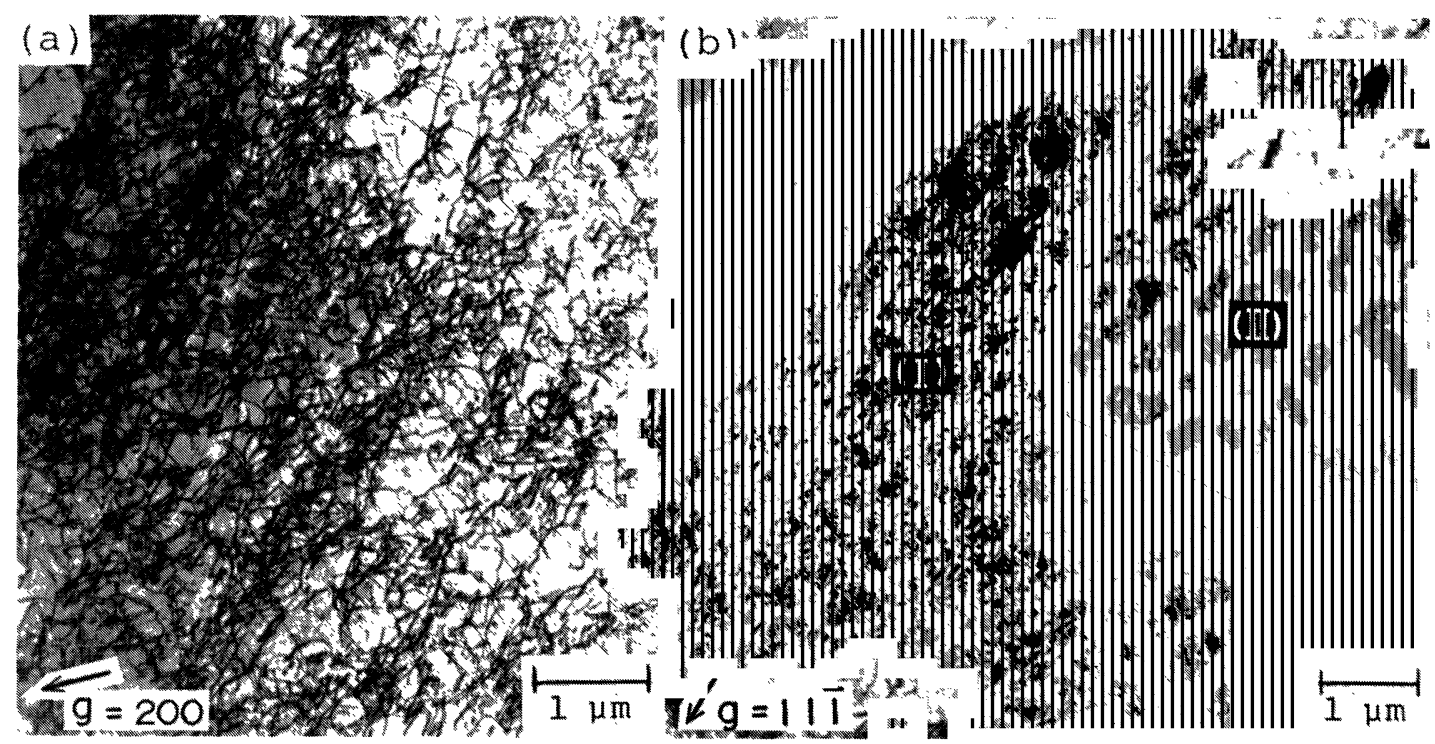

$\begin{array}{ll}\text { (a) } 5 \text { cycles } & \text { (b) } 250 \text { cycles }\end{array}$

Photo. 3. Dislocation structure of $\mathrm{N}$ steel fatigued at $\varepsilon_{t}=1.6 \%$, room temperature.

formed. (b) shows a dislocation structure after cyclic softening to saturation is attained. It should be noted that the grain consists of the region (I) of the dislocation structure, which is the same as that observed in Photo. 3(a), and the region (II) of a well developed cell structure, similar to that observed in Photo. 1(b).
Photograph 4 shows the change in dislocation structure of $\mathrm{N}$ steel fatigued at $-162{ }^{\circ} \mathrm{C}$. (a) represents a dislocation structure after 5 cycles (at peak stage). It can be seen that dislocations are activated locally and the region where no deformation takes place is still present. This indicates that the cross slip of dis- 


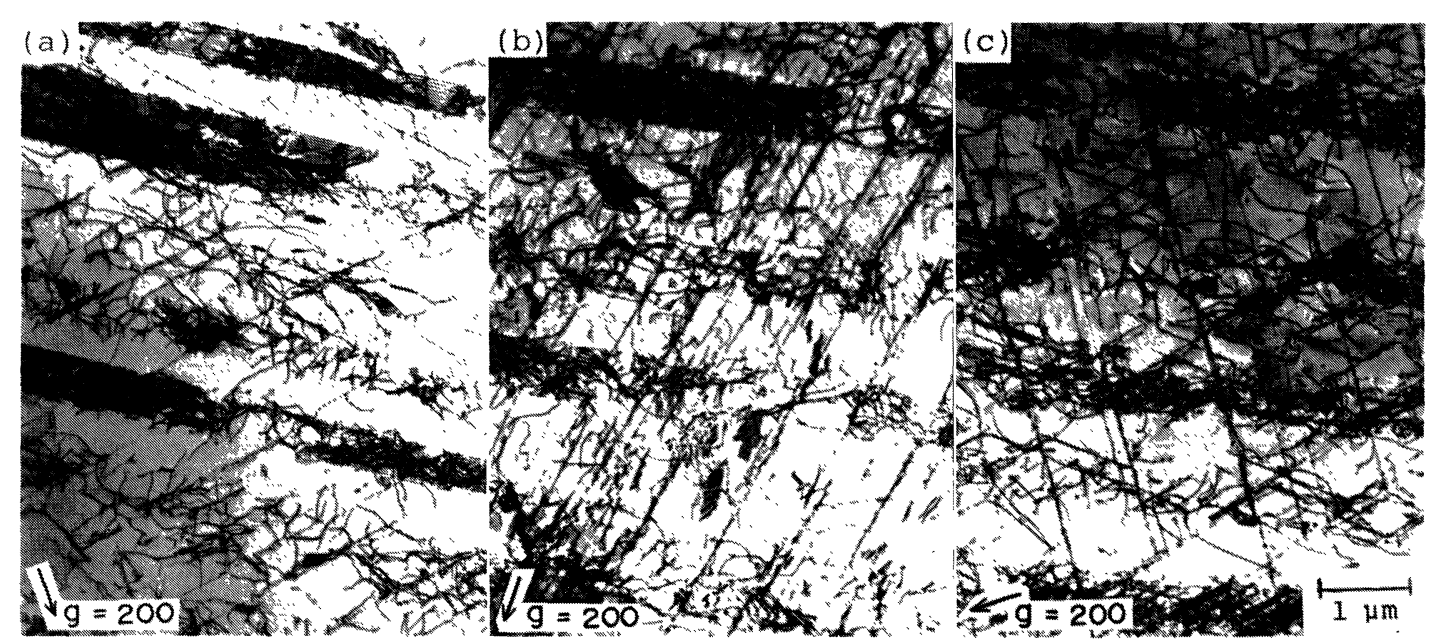
(a) 5 cycles
(b) 30 cycles
(c) 250 cycles

Photo. 4. Dislocation structure of $\mathrm{N}$ steel fatigued at $\varepsilon_{t}=1.6 \%,-162{ }^{\circ} \mathrm{C}$.

locations is strongly suppressed and dislocation movements are restricted on their slip planes. (b) shows a dislocation structure during cyclic softening stage. Although the density of slip bands appears to increase, dislocation movements are still restricted in their slip bands. (c) shows a dislocation structure at a transition stage from cyclic softening to saturation. The appearance of dislocation structure is similar to that of (b), although slip bands are not as clear as those observed in (a). However, even in the saturation stage a cellular type of dislocation structure is not formed.

\section{Fatigue Life at Plastic Strain Range}

Figure 10 shows the fatigue lives as a function of averaged plastic strain range $\left(\bar{\varepsilon}_{p}\right)$ at various temperatures. $\bar{\varepsilon}_{p}$ was taken as $\varepsilon_{p}$ at the cyclic saturation stage, except for $\mathrm{L}$ steel fatigued at $-162{ }^{\circ} \mathrm{C}$ where no cyclic hardening to saturation was observed. In this case, the plastic strain range at $1 / 2 n_{f}$ was chosen as $\bar{\varepsilon}_{p}$. It can be seen that as the testing temperature decreases $n_{f}$ of $\mathrm{L}$ steel decreases but that of $\mathrm{N}$ steel increases. Moreover, under the same fatigue condition $\mathrm{N}$ steel exhibits a longer $n_{f}$ than $\mathrm{L}$ steel. This means that $\mathrm{N}$ has a strong influence to improve the fatigue life of austenitic stainless steel.

\section{Discussion}

1. Effect of $\mathrm{N}$ on Dynamic Characteristics and Microstructural Behavior at Cyclic Hardening Stage

It is well known that the cyclic deformation behaviors of FCG metals and alloys depend strongly on their stacking fault energies (SFE). The cross slip of dislocations is easier for higher SFE, which increases the interaction between dislocations, resulting in the increase in work hardening. ${ }^{5)}$ Avery and Backofen ${ }^{6}$ ) have reported this behavior for $\mathrm{Cu}$ and $\mathrm{Cu}-\mathrm{Al}$ alloys. The cyclic hardening rate of the present alloy, which can be calculated by $\Delta \sigma_{h} / \sigma_{n=1}$, is $33 \%$ and $18 \%$ for $\mathrm{L}$ and $\mathrm{N}$ steels, respectively. This means that $\mathrm{N}$ de* creases the cyclic hardening. On the other hand, N

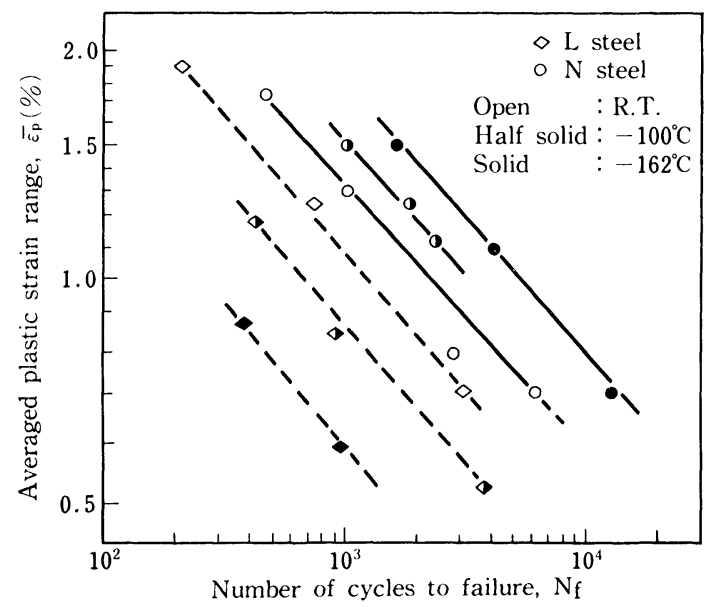

Fig. 10. Effects of $\mathrm{N}$ and temperature on fatigue life.

inhibits cross-slip of dislocations, and promotes a planar distribution of dislocations. Therefore, it can be expected that $\mathrm{N}$ decreases the SFE of austenitic stainless steels.

However, most of the measurements of SFE by transmission electron microscopy ${ }^{2,3,7,8)}$ and X-ray diffractometry ${ }^{9,10)}$ show that $\mathrm{N}$ does not influence or little lowers SFE. Thus, it can not be concluded that the decrease in cyclic hardening rate and the planar distribution of dislocations is attributed to the decrease in the SFE by the addition of N. Swann ${ }^{2}$ and Douglass $^{3)}$ have postulated in $\mathrm{Fe}-18 \mathrm{Cr}-(8 \sim 24) \mathrm{Ni}$ and $\mathrm{Fe}-20 \mathrm{Cr}-40 \mathrm{Ni}$ alloys that the planar distribution of dislocations is attributed to a short range ordered zone (SRO-zone) formed by $\mathrm{Fe}-\mathrm{Cr}$ and $\mathrm{N}$. Under this condition, mobile dislocations may be piled up by the SRO-zone. As the density of pile-up dislocations increases, the internal stress also increases and when the internal stress overcomes the resistance of SRO-zone against mobile dislocation, dislocations cut through the zone. Subsequently, the pile-up dislocations can move easily on their slip planes without cross-slip, resulting in the formation of planar distribution. 
Although there have been no evidences that there exists the SRO-zone in $\mathrm{Fe}-18.5 \mathrm{Cr}-15 \mathrm{Ni}$ alloy, the following results of tensile test can evidently support the presence of the SRO-zone.

It has been already reported that $\mathrm{N}$ induces a strong temperature dependence of the yield stress. ${ }^{11)}$ In general, a flow stress is consisted of an athermal component $\left(\sigma_{i}\right)$ and of a thermal component $\left(\sigma^{*}\right) \cdot{ }^{12)}$ In order to separate these components, it can be roughly assumed that the yield stress at room temperature is $\sigma_{i}$, and the difference between the yield stress at low temperature and $\sigma_{i}$ is $\sigma^{*}$.*

Figure 11 shows a relation between $\sigma^{*}$ and $\sqrt{T}$. It can be clearly seen that there exist linear relations between $\sigma^{*}$ and $\sqrt{T}$. By extrapolating these lines to $0{ }^{\circ} \mathrm{K}$, the thermal component of yield stress at $0^{\circ} \mathrm{K}$, $\sigma_{0}^{*}$, can be obtained for various contents of $\mathrm{N}$ and $\mathrm{C}$.

Figure 12 shows the dependence of $\sigma_{0}^{*}$ on $\sqrt{\mathrm{N}}$ and $\sqrt{\mathrm{C} .}$ It is noted that $\sigma^{*}$ increases linearly with $\sqrt{\mathrm{N}}$. This result strongly suggests that the mechanism of solid solution hardening of $\mathrm{Fe}-\mathrm{Cr}-\mathrm{Ni}$ alloy by the addition of $\mathrm{N}$ can be explained by Fleischer's theory. ${ }^{13)}$ According to the theory, mobile dislocations at low temperature interact with a kind of resistant zone in a short range stress field, which substantially increase the thermal component of the flow stress.

Since the resistant zone can be considered as the SRO-zone, it is postulated that SRO-zone can be formed in the present alloy by the addition of $\mathrm{N}$.

As the testing temperature decreases, $\sigma_{n=1}$ increases. Microstructurally, dislocation activity is very restricted within slip bands. Thus, under the activation process of the present alloy, once dislocation overcomes the stress field of the SRO-zone, subsequent mobile dislocations can move on their slip plane under lower stress field without cross-slip. As a result, interactions between planar dislocations are weak, so that the cyclic hardening rate at low temperature is much smaller than that at room temperature.

\section{Effect of $\mathrm{N}$ on Cyclic Softening Behavior}

As has been shown in Fig. 6, $\mathrm{N}$ steel exhibits a cyclic hardening, followed by cyclic softening to saturation. The cyclic hardening-softening behavior is observed in cold worked materials, in which dislocations introduced by cold work are rearranged into a more stable structure with respect to cyclic deformation. The cyclic softening due to dislocation rearrangement is also observed in martensitic steels. ${ }^{14,15}$ )

For annealed materials, cyclic softening is observed in materials which have high yield strength and low

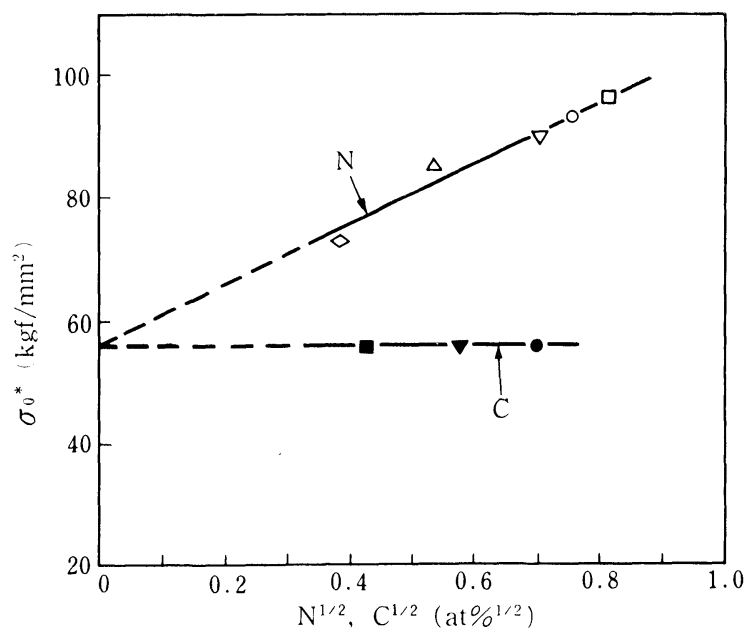

Fig. 12. Effect of nitrogen and carbon on thermal component of yield stress at $0^{\circ} \mathrm{K}$.

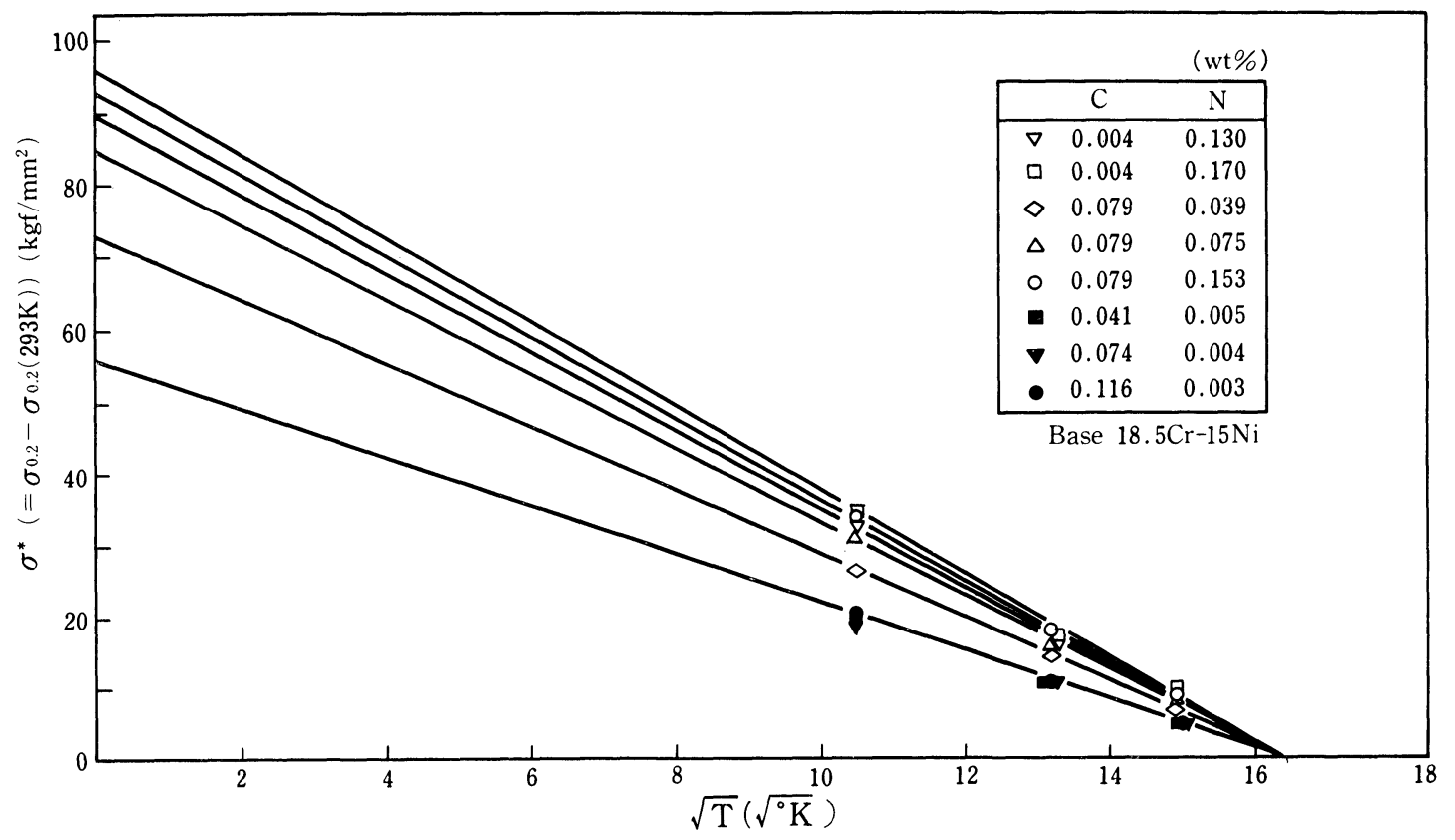

Fig. 11. Relation between thermal component of yield stress $\left(\sigma^{*}\right)$ and $\sqrt{ } \bar{T}$.

\footnotetext{
* The yield stress at room temperature is not all $\sigma_{i}$. However it is presumed that the temperature dependence of yield stress is low at the temperature range between $20^{\circ} \mathrm{C}$ and $200^{\circ} \mathrm{C}$. Thus, it can be assumed that the yield stress at room temperature is $\sigma_{i}$. Since $\sigma_{i}$ is not dependent on the temperature, ${ }^{12)}$ the increase in yield stress by lowering testing temperature can also be assumed to be $\sigma^{*}$.
} 
work hardening rate. ${ }^{\mathbf{1 6 - 1 8})}$ The softening is also observed in materials containing precipitates ${ }^{19)}$ or ordering ${ }^{20,21)}$ which can be penetrable by mobile dislocations. It has been suggested in this case that the cyclic softening is attributed to the cutting of precipitates or ordering by repeated motion of dislocations.

In austenitic stainless steels the cyclic softening is observed in AISI202, ${ }^{22)}$ SUS304 and SUS310.23) Shibata et al. ${ }^{23)}$ have suggested a possibility that the softening is due to the increase in mobile dislocation density.

In $\mathrm{N}$ steel of the present austenitic stainless steel, it has been proposed that the cyclic softening at room temperature is attributed to the rearrangement of planar dislocations introduced uniformly in the matrix to cellular ones which are more stable with respect to cyclic deformation. On the other hand, the cyclic softening at low temperature is attributed to the increase in mobile dislocation density in the slip bands.

However, mechanisms of these cyclic softenings are postulated from the phenomenological point of view and there still remains open the questions how the addition of $\mathrm{N}$ induces the dislocation rearrangement or the increase in mobile dislocation density.

As has been already shown in Fig. $9, \Delta \sigma_{s}^{*}$ decreases with lowering the testing temperature and becomes negative below $-100^{\circ} \mathrm{C}$. This means that at low temperature the cyclic deformation at the saturation stage takes place at lower stress range than at the early stage of deformation. In the present alloy, it can be presumed that the stress range at an early stage of deformation is controlled by the frictional stress between dislocation and the SRO-zone, while the stress range at a later stage of cyclic deformation is controlled by the interaction between dislocations in the stress field which is stable with respect to cyclic deformation. In the case of room temperature, the thermal component of the flow stress is small and a large number of dislocation sources are activated. However, due to the presence of the SRO-zone, cross slip of dislocations is inhibited and the dislocations exhibit a planar distribution through the matrix. As the internal stress which increases with the increase in the density of planar dislocations reaches a critical level, the resistance of SRO-zone against mobile dislocations is no longer high enough and dislocations begin to cross slip, resulting in the relaxation of internal stress.

By contrast, it has been suggested that when the steel is cycled at low temperature the thermal component of the flow stress is so high that the interaction between dislocations and the SRO-zone in the short range stress field is substantially large. Once slip bands are activated by cyclic deformation, the resistance of SRO-zone is weakened. Thus, the subsequent cyclic deformation takes place by dislocation activity within the locally activated slip bands. At the saturation stage the stress range is controlled by the interaction between mobile dislocations in the activated slip bands where the influence of SRO-zone has already been destroyed. Therefore, the stress range at the saturation stage is lower than that at the early stage of cyclic deformation.
To summarize the above discussion, the SRO-zone is formed by the addition of $\mathrm{N}$ and the interaction between SRO-zone and dislocations is responsible for the cyclic hardening-softening behaviors. Especially at low temperature, the thermal component of flow stress increases and the interaction between the SRO-zone and dislocations which takes place in the short range stress field is responsible for the cyclic behavior.

\section{Effect of $\mathrm{N}$ on Low Cyclie Fatiguc Life}

$\mathrm{N}$ steel has longer fatigue life than $\mathrm{L}$ steel over the whole strain range and the fatigue life of $\mathrm{N}$ steel increases with decreasing the testing temperature. Thus, it is suggested that there must exist a correlation between the fatigue life and the cyclic hardeningsoftening behavior.

It has been shown in Fig. 9 that $\Delta \sigma_{h}$ at room temperature decreases by the addition of $\mathrm{N}$ and as the testing temperature decreases $\Delta \sigma_{h}$ of $\mathrm{L}$ steel increases, while that of $\mathrm{N}$ steel decreases. It was also reported on steels having metastable austenite phase that the fatigue life decreases with the increase of $\Delta \sigma_{h} .{ }^{1)}$ Thus, it may be concluded that the addition of $\mathrm{N}$ increases the fatigue life by reducing the cyclic hardening which accumulates fatigue damages.

From the microstructural point of view, when fatigued at room temperature, $\mathrm{N}$ delays the formation of the cell structure. At low testing temperature, on the other hand, $\mathrm{N}$ restricts the dislocation activities in very localized slip bands, which decreases $\Delta \sigma_{h}$ and increases $\Delta \sigma_{s}$. Moreover, as has been shown in Fig. 7, the number of cycles to reach the cyclic softening to saturation increases with lowering the testing temperature. Therefore, it is presumed that the interaction between dislocations and the SRO-zone in the short range stress field takes place until the later stage of cyclic deformation, which remarkably suppresses the accumulation of fatigue damages and further increases the fatigue life.

\section{Conclusions}

The effect of $\mathrm{N}$ on low cycle fatigue behavior of austenitic stainless steel has been investigated at a temperature range between room temperature and $-162{ }^{\circ} \mathrm{C}$. The main results obtained are as follows;

(1) At an early stage of cyclic deformation $\mathrm{N}$ induces a strong temperature dependence of stress range and decreases the cyclic hardening. At the same time $\mathrm{N}$ promotes a planar distribution of dislocations.

(2) $\mathrm{N}$ induces a cyclic hardening followed by cyclic softening to saturation. As the testing temperature decreases the cyclic hardening decreases but the cyclic softening increases. Especially, at testing temperatures below $-100^{\circ} \mathrm{C}$ the cyclic deformation at the saturation stage takes place at lower stress range than at the early stage of deformation.

(3) It is proposed that the cyclic softening at room temperature is attributed to the rearrangement of planar dislocations to cellular ones, while at low temperature it is attributed to the increase in mobile dislocation density in localized slip bands.

(4) The cyclic hardening-softening behavior and 
the strong temperature dependence of stress range at an early stage of cyclic deformation suggest that the SRO-zone is formed by the addition of N. Especially at low temperature the thermal component of stress range becomes so large that the cyclic behavior is controlled by the interaction between dislocations and the SRO-zone in a short range stress field.

(5) $\mathrm{N}$ improves the fatigue life by inducing cyclic hardening-softening behavior. The lowering of testing temperature further improves the fatigue life by the strong interaction between the dislocations and the SRO-zone in a short range stress field, which suppresses the accumulation of fatigue damages.

\section{REFERENCES}

1) K. Hoshino and K. Mukai: Tetsu-to-Hagané, 69 (1975), 631.

2) P. R. Swann: Corrosion, 19 (1963), 102.

3) D. L. Douglass, G. Thomas and W. R. Roser: Corrosion, 20 (1964), 15t.

4) K. Hoshino, K. Itoh and T. Komatsu: Nisshin Steel Tech. Rep., (1973), No. 29, 26.

5) C. E. Feltner and C. Laird: Acta Met., 15 (1967), 1621.

6) D. H. Avery and W. A. Backofen: Acta Met., 11 (1963), 653.

7) R. Fawley, M. A. Quader and R. A. Dodd: Trans. AIME, 242 (1968), 771.
8) D. Dulieu and J. Nutting: Iron and Steel Inst. Spec. Rep., 86 (1964), 140

9) R. E. Schramm and R. P. Reed: Met. Trans., 6A (1975), 1345.

10) M. Fujikura, K. Takada and K. Ishida: Trans. ISIJ, 15 (1975), 464.

11) T. Takemoto, K. Mukai and K. Hoshino: Tetsu-to-Hagané, 63 (1983), A89.

12) H. Conrad: J. Metals, 16 (1964), 582.

13) R. L. Fleischer: The Strength of Metals, Reinhold Pub. Co., New York, (1964), 93.

14) L. F. Van Swam, R. M. Pelloux and N. J. Grant: Met. Trans., 6A (1975), 45.

15) P. N. Thielen, M. E. Fine and R. A. Fournelle: Acta Met., 24 (1976), 1.

16) R. Stevenson and J. F. Breedis: Acta Met., 23 (1975), 1419.

17) C. G. Wojcik and D. A. Koss: Mat. Sci. and Eng., 27 (1977), 97.

18) S. B. Chakrabortty, T. M. Mukhopadhyay and E. A. Starke, Jr.: Acta Met., 26 (1978), 909.

19) C. Calabrase and C. Laird: Mat. Sci. and Eng., 13 (1974), 141.

20) C. H. Wells and C. P. Sullivan: Trans. ASM, 57 (1964), 841.

21) C. E. Feltner and P. Beardmore: ASTM Spec. Tech. Publ., No. 467, (1970), 77.

22) G. Franke and C. Altstetter: Met. Trans., 7A (1976), 1719.

23) K. Shibata, N. Namura, Y. Kishimoto and T. Fujita: Tetsu-to-Hagané, 69 (1983), 2076. 